\title{
Extensive Micro-Structuring of Metals using Picosecond Pulses - Ablation Behavior and Industrial Relevance
}

\author{
Frank SIEGEL $^{* 1}$, Ulrich KLUG ${ }^{* 1}$ and Rainer KLING ${ }^{* 1}$ \\ ${ }^{* 1}$ Laser Zentrum Hannover e.V., Hollerithallee 8, 30419 Hannover, Germany \\ f.siegel@lzh.de
}

\begin{abstract}
The micro-structuring of technical metallic surfaces is an effective technique to change their mechanical, chemical or fluidic characteristics. Based on increasing demands on the capability of technical surfaces, for example, higher process resolution for texture geometries in the $\mu \mathrm{m}$-range as well as excellent process stability and reproducibility, an increased level of surface technologies is developing. Laser-based generation of defined micro structures on extensive metallic surfaces is under development. Micro-machining of metals using a diode-pumped, regenerative-amplified ps$\mathrm{Nd}: \mathrm{YVO}_{4}$-laser source has been investigated. Eight different metals and a metallic alloy (Al, $\mathrm{Cu}, \mathrm{Fe}$, $\mathrm{Mg}, \mathrm{Ni}, \mathrm{Pb}, \mathrm{Ti}, \mathrm{W}$ and $\mathrm{X} 20 \mathrm{Cr} 13$ ) have been investigated concerning the ablation rate per pulse, ablation geometry, formation of melt phase, influence of pulse overlap and number of loops. The ablation characteristics are correlated with thermal conductivity, specific heat capacity and the melting temperature regarding processing window and machining throughput. Based on the presented results, the generation of rib-structures, so-called riblets, are fabricated on compressor blades and tested in a cascade wind tunnel. The achieved improvement of skin friction reduction as well as an efficiency-consideration regarding industrial applications and their demands will be discussed. DOI: $10.2961 / \mathrm{jlmn} .2009 .02 .0006$
\end{abstract}

Keywords: laser, micro-machining, picosecond, ablation behavior, riblets

\section{Introduction}

Picosecond (ps) lasers potentially combine the high process speed of nanosecond lasers with the excellent machining quality of femtosecond (fs) lasers. Recent enhancements of laser manufacturers address two major industrial needs: Multiplication of output power as well as robust and mature laser products. These features enable industrial applications in various fields where highest machining accuracy and process speed is needed combined with a minimum of thermal damage to the work piece [1].

Corresponding to the two basic power multiplication concepts - increase of pulse energy and/or the repetition rate - ps-lasers facilitate the fabrication of new and innovative products and become more attractive for the substitution of conventional laser micromachining processes $[2,3]$.

The presented extensive micro-structuring application for the generation of riblets, by means of area sizes in the range of $100 \mathrm{~cm}^{2}$ and above, benefits from these new laser products and features. The short pulse duration of about 12 ps enables micro structures with the required quality and reproducibility, while repetition rates up to $500 \mathrm{kHz}$ combined with necessary pulse energy open new machining strategies to achieve throughput and process efficiency at an industrial standard.

To establish a basis for the generation of riblets, basic considerations were done in the beginning regarding the ablation behavior of metallic elements using $12 \mathrm{ps}$ pulse duration. Ablation rates per pulse as well as thermal effects have been determined in dependency to the average fluence per pulse and thermo physical properties of the selected metallic elements.

\section{Materials and machining setup}

Table 1: Laser specifications

\begin{tabular}{ccc}
\hline Wavelength & $\lambda$ & $1064 \mathrm{~nm}$ \\
Pulse repetition rate & $\mathrm{f}_{\mathrm{P}}$ & $50 \mathrm{kHz}$ \\
Pulse duration (FWHM) & $\tau_{\mathrm{P}}$ & $12 \mathrm{ps}$ \\
Pulse energy & $\mathrm{E}_{\mathrm{P}}$ & $120 \mu \mathrm{J}$ \\
Output power & $\mathrm{P}_{\varnothing}$ & $6 \mathrm{~W}$ at $50 \mathrm{kHz}$ \\
Beam quality & $\mathrm{M}^{2}$ & 1.7 \\
Beam diameter & $\mathrm{d}_{\mathrm{B}}$ & $8 \mathrm{~mm}$ \\
Focal length & $\mathrm{f}_{\mathrm{F}}$ & $100 \mathrm{~mm}$ \\
Focal diameter (calc.) & $\mathrm{d}_{\mathrm{F}}$ & $28.8 \mu \mathrm{m}$ \\
\hline
\end{tabular}

The laser source used for the experiments is a diodepumped, regenerative-amplified $\mathrm{Nd}-\mathrm{YVO}_{4}$ solid-state laser (Staccato, LUMERA LASER GmbH). The relative motion between laser beam and sample has been realized by a galvanometer scanner system. Main specifications of the machining setup are given in Table 1.

Eight different metallic elements have been selected for the experiments presented in this paper. The metallic alloy $\mathrm{X} 20 \mathrm{Cr} 13$ (chromium steel) is selected to address the industrial application of this paper, which focuses on the improvement of fluidic parts by surface structuring. X20Cr13 is a typical material for compressor blades and shall be representatively provided with laser-structured riblets for skin friction reduction. Thermo-physical properties such as melting temperature $T_{m}$, thermal conductivity $\kappa_{\text {th }}$ and specific heat capacity $c_{P}$ are summarized in the following section in Table 2 regarding the ablation behavior. 


\section{Experiments}

\subsection{Basic considerations for comparability reasons}

The same machining procedure is used for all materials. The ablation characteristics are determined by line-shaped material removals on the material surface. The parameters pulse energy $E_{P}$, pulse overlap $o_{P}$ (by changing the feed rate at constant pulse repetition rate) as well as the number of repetitions per line $\mathrm{N}$ are varied. The ablation depth of the lines is limited to $50 \mu \mathrm{m}$ to avoid deviations by shadowing or side wall reflections inside the generated channels.

To achieve the ablation rate per pulse by means of ablation depth for each single pulse, the depth of the generated lines is measured by optical microscopy. Division of these depth values by the number of repetitions as well as by the number of active pulses $\mathrm{N}_{P}$ at each point (pulses that hit the same point of material surface) along the ablated line, the values for $a_{P}$ are determined. The number of active pulses $N_{P}$ is calculated with the repetition rate $f_{P}$, the calculated focal diameter $d_{f}$ and the feed rate $\mathrm{v}$ by equation 1 :

$$
N_{P}=\frac{f_{P} \cdot d_{F}}{v}
$$

and the pulse overlap $o_{\mathrm{P}}$ is calculated using equation 2 :

$$
o_{P}=\left(1-\frac{1}{N_{P}}\right) \cdot 100 \%
$$

To figure out the principle ablation behavior of metals using ps pulse duration and to understand the interaction processes between laser beam and matter, the ablation rate per pulse $a_{P}$ against the average fluence per pulse $H_{P}$ has been determined for different explanatory variables. $\mathrm{H}_{\mathrm{P}}$ has been determined by equation 3 (see Table 1):

$$
H_{P}=\frac{E_{P}}{A_{F}}=\frac{4 \cdot E_{P}}{\pi \cdot d_{F}^{2}}=\frac{4 \cdot E_{P}}{\pi \cdot\left[\frac{4 \cdot \lambda \cdot f_{F}}{\pi \cdot d_{B}} \cdot M^{2}\right]^{2}}
$$

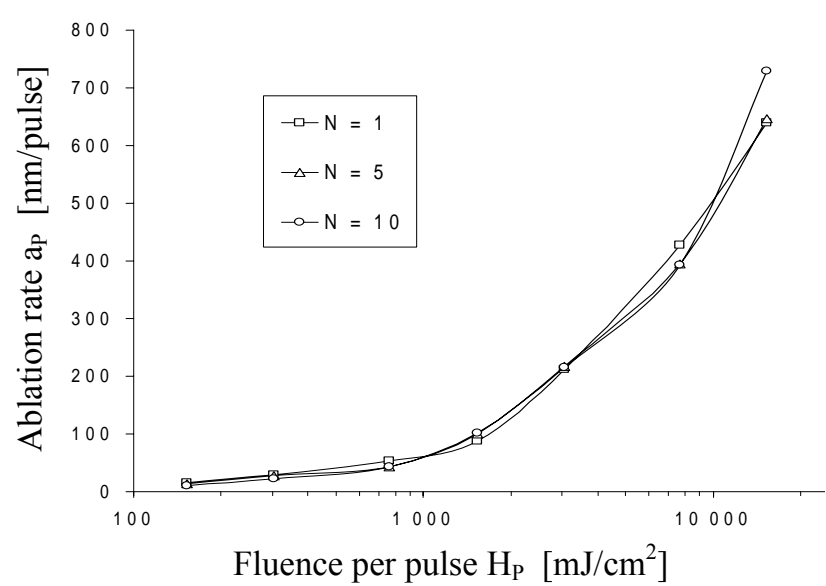

Figure 1: Influence of number of repetitions $\mathrm{N}$ on the ablation rate $\mathrm{a}_{\mathrm{p}}$ for example for Magnesium
In a first step, the influence of number of repetitions $\mathrm{N}$ as well as the pulse overlap $o_{P}$ has been investigated. For a single line $(\mathrm{N}=1)$, the laser interacts with the unexposed surface, while for the following repetitions $(\mathrm{N}>1)$ the pulses interact with exposed surface areas. This is supposed to influence the values of ap.

It has to be mentioned, that even for a single line ablation the next following pulse hits exposed material from the previous one, depending on the pulse overlap. Figure 1 shows achieved results, for example for Magnesium, at pulse overlap of about $\mathrm{o}_{\mathrm{P}}=86 \%$.

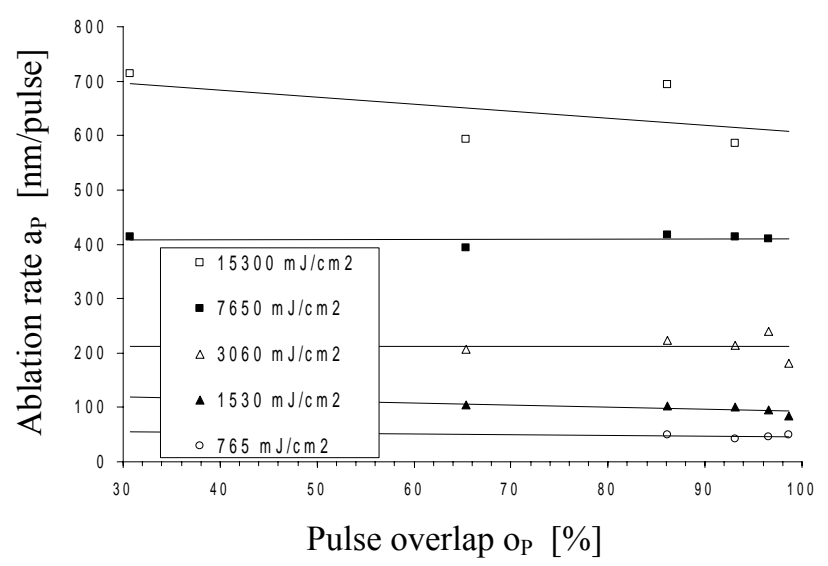

Figure 2: Influence of the pulse overlap op on the ablation rate $a_{p}$ for example for Magnesium

For the same fluence values and a maximum ablation depth of $50 \mu \mathrm{m}$, the number of repetitions has no influence on the ablation rate. An equal behavior can be observed for different pulse overlap values, as shown in Figure 2. For each fluence value nearly constant ablation rates have been achieved. All tested materials show this independence of $\mathrm{N}$ and $\mathrm{o}_{\mathrm{P}}$.

The influence of fluence per pulse $\mathrm{H}_{\mathrm{P}}$ on the ablation behavior, in this case for example for $\mathrm{X} 20 \mathrm{Cr} 13$, is shown in Figure 3.

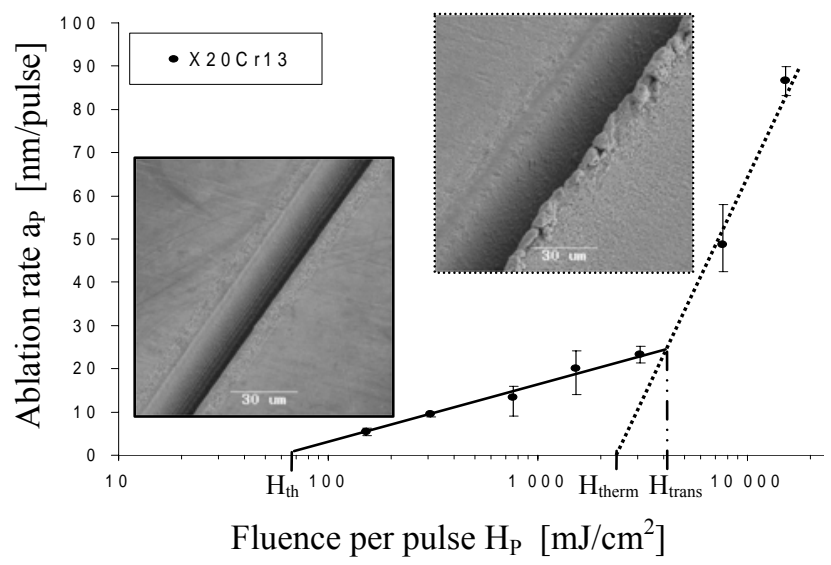

Figure 3: Ablation behavior of $\mathrm{X} 20 \mathrm{Cr} 13$ using pulse duration of $\tau_{\mathrm{P}}=12 \mathrm{ps}, \lambda=1064 \mathrm{~nm}$

Corresponding to the ablation behavior of metals for fs pulse duration, the use of ps pulses leads also to two char- 
acteristic ablation regimes $[4,5]$. The solid-lined curve in Figure 3 can be described by the following equation 4 :

$$
a_{P}=\delta_{o p t} \cdot \ln \left(\frac{H_{P}}{H_{t h}}\right)
$$

Equation 4 [4] characterizes ablation within a time regime where heat conduction outside the optical penetration depth $\delta_{\text {opt }}$ can be neglected. The characteristic value $\mathrm{H}_{\text {th }}$ specifies the ablation threshold for this material. Within this "optical regime" the ablation rate $a_{p}$ for $\mathrm{X} 20 \mathrm{Cr} 13$ could not exceed $25 \mathrm{~nm} /$ pulse. The achievable edge and surface quality is comparable to results of experiments done with fs pulses.

The dotted curve in Figure 3 describes the "thermal regime" and is given by equation 5 [4]:

$$
a_{P}=\delta_{\text {therm }} \cdot \ln \left(\frac{H_{P}}{H_{\text {therm }}}\right)
$$

Within the thermal regime, a significant part of the absorbed pulse energy is conducted by electron diffusion beyond the optical penetration depth $\delta_{\text {opt }}$ and leads to further ablative interaction with the surrounding material. Due to the hot electron diffusion the extent of the ablation regime is called thermal penetration depth $\delta_{\text {therm }}$. The advantages of higher ablation rates up to $100 \mathrm{~nm} /$ pulse are coupled with a clearly reduced surface quality and the formation of burr as well as melting zones along the irradiated areas. The material specific fluence $\mathrm{H}_{\text {trans }}$ indicates the transition fluence from non-thermal to the thermal ablation. For X20Cr13 we determine a transition fluence of about $3360 \mathrm{~mJ} / \mathrm{cm}^{2}$.

It has to be mentioned that both regimes are characterized by an ablation process of thermal nature. The only difference is the characteristic length of energy penetration. For clarity these two regimes were separated into optically dominated and thermal (conduction dominated) one, in spite of their common thermal character.

\subsection{Correlation between thermo physical properties and ablation characteristics}

Based on the results presented in section 3.1, the ablation rate per pulse ap has been determined for eight selected metals. To make these results comparable among each other, the following assumption was made:
The dynamic change of the thermal conductivity $\kappa_{\mathrm{th}}$ and the specific heat capacity $c_{P}$ by changing the temperature will be neglected and supposed to be constant.
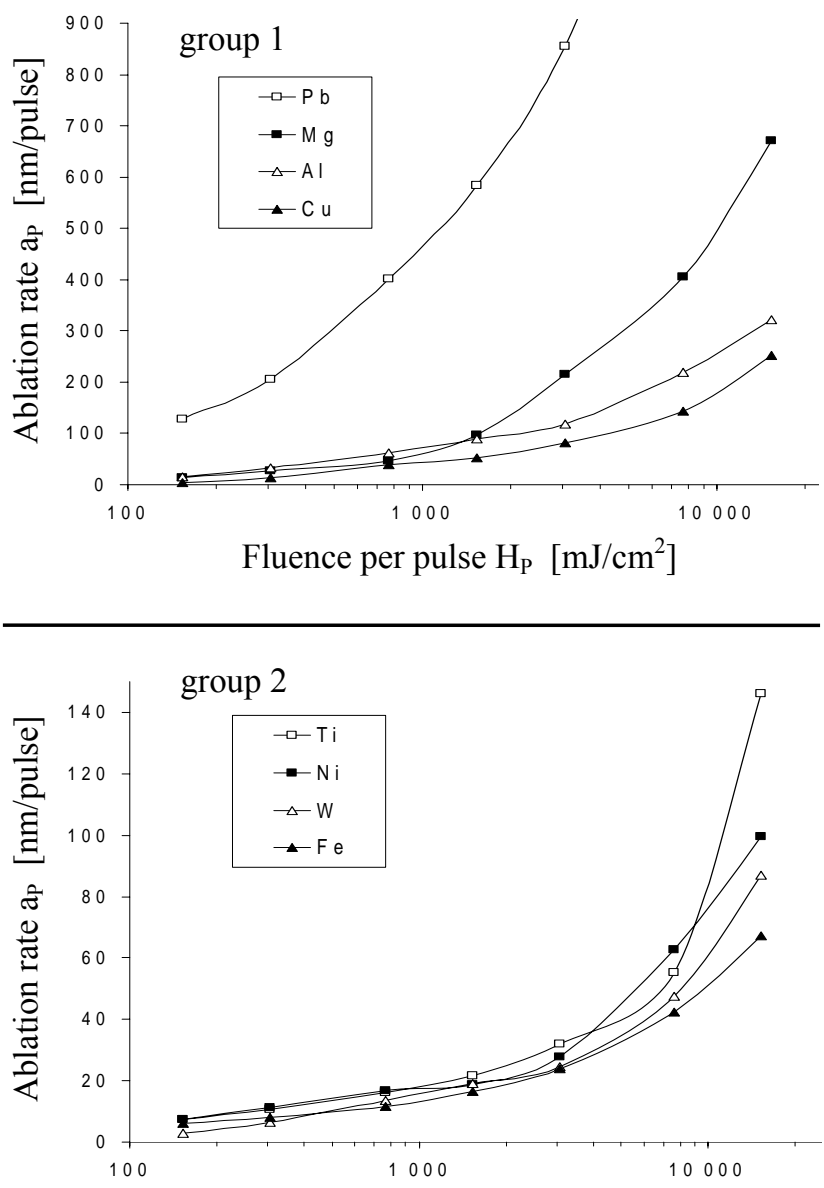

Fluence per pulse $H_{P}\left[\mathrm{~mJ} / \mathrm{cm}^{2}\right]$

Figure 4: Ablation behavior of selected metals using pulse duration of $\tau_{\mathrm{P}}=12 \mathrm{ps} @ \lambda=1064 \mathrm{~nm}$

The reflection coefficient $\mathrm{R}$, which is for the investigated metals between 0.55 and 0.85 , will also be neglected. The stated values for $\mathrm{R}$ in the literature are ranging, for example for $\mathrm{Al}$ we found values between 0.62 and 0.94 , or could not be found for the used wavelength. Due to these facts, the reflection coefficient $\mathrm{R}$ will not be part of the discussion, in spite of its well known influence on the total quantity of absorbed energy.

\begin{tabular}{|c|c|c|c|c|c|c|c|c|c|c|c|c|c|}
\hline Material & $\begin{array}{c}\alpha \\
{\left[\mathrm{cm}^{-1}\right]}\end{array}$ & $\begin{array}{c}\delta_{\mathrm{opt}} \\
{[\mathrm{nm}]}\end{array}$ & $\begin{array}{c}\mathrm{D} \\
{\left[\mathrm{cm}^{2} / \mathrm{s}\right]}\end{array}$ & $\begin{array}{l}\delta_{\text {therm }} \\
{[\mathrm{nm}]}\end{array}$ & $\begin{array}{c}R \\
{[---]}\end{array}$ & $\begin{array}{c}\mathrm{T}_{\mathrm{m}} \\
{[\mathrm{K}]}\end{array}$ & $\begin{array}{c}\mathrm{T}_{\mathrm{b}} \\
{[\mathrm{K}]}\end{array}$ & $\begin{array}{c}\kappa \\
{[\mathrm{W} / \mathrm{cm} \cdot \mathrm{K}]}\end{array}$ & $\begin{array}{c}\mathrm{c}_{\mathrm{P}} \\
{[\mathrm{J} / \mathrm{g} \cdot \mathrm{K}]}\end{array}$ & $\underset{\left[\mathrm{mJ} / \mathrm{cm}^{2}\right]}{\mathrm{H}_{\mathrm{th}}}$ & $\underset{\left[\mathrm{mJ} / \mathrm{cm}^{2}\right]}{\mathrm{H}_{\text {therm }}}$ & $\begin{array}{c}\mathrm{H}_{\text {trans }} \\
{\left[\mathrm{mJ} / \mathrm{cm}^{2}\right]}\end{array}$ & $\begin{array}{c}\mathrm{a}_{\mathrm{P}} @ \mathrm{H}_{\text {trans }} \\
{[\mathrm{nm}]}\end{array}$ \\
\hline $\mathrm{Pb}$ & $6.69 \cdot 10^{5}$ & 15 & 0.24 & 17 & - - - & 601 & 2020 & 0.35 & 0.13 & 70 & 470 & 1090 & 415 \\
\hline $\overrightarrow{2}^{\mathrm{Mg}}$ & $9.40 \cdot 10^{5}$ & 11 & 0.87 & 32 & - - & 923 & 1370 & 1.56 & 1.03 & 101 & 1350 & 1780 & 73 \\
\hline$\overline{\mathrm{O}} \mathrm{Al}$ & $1.03 \cdot 10^{6}$ & 10 & 1.03 & 35 & $\sim 0.8$ & 933 & 2770 & 2.37 & 0.90 & 102 & 1240 & 2920 & 108 \\
\hline${ }^{600} \mathrm{Cu}$ & $7.69 \cdot 10^{5}$ & 13 & 1.14 & 37 & $\sim 0.85$ & 1360 & 2840 & 4.00 & 0.39 & 141 & 1560 & 2970 & 67 \\
\hline $\mathrm{Ti}$ & $3.84 \cdot 10^{5}$ & 26 & 0.094 & 11 & 0.55 & 1940 & 3560 & 0.22 & 0.52 & 61 & 3350 & 4660 & 30 \\
\hline$\stackrel{N}{2} \mathrm{Ni}$ & $6.21 \cdot 10^{5}$ & 16 & 0.24 & 17 & 0.69 & 1730 & 3190 & 0.89 & 0.44 & 32 & 1710 & 2860 & 23 \\
\hline 亏ె్ㅐ W & $4.06 \cdot 10^{5}$ & 25 & 0.65 & 28 & 0.59 & 3700 & 5830 & 1.78 & 0.13 & 114 & 2840 & 4880 & 27 \\
\hline${ }^{\infty} \mathrm{Fe}$ & $6.24 \cdot 10^{5}$ & 16 & 0.23 & 17 & 0.64 & 1810 & 3080 & 0.80 & 0.46 & 40 & 1190 & 2360 & 17 \\
\hline $\mathrm{X} 20 \mathrm{Cr} 13$ & - - - & $\ldots$ & 0.085 & 10 & - - & 1780 & 3200 & 0.30 & 0.46 & 62 & 1560 & 2890 & 22 \\
\hline
\end{tabular}

Table 2: Thermo physical and optical properties as well as ablation characteristics of selected metals $[6,11,12]$ 
Figure 4 shows the relation between the fluence $\mathrm{H}_{\mathrm{P}}$ and the resulting $\mathrm{a}_{\mathrm{p}}$ for $\mathrm{Pb}, \mathrm{Mg}, \mathrm{Al}$ and $\mathrm{Cu}$ (summarized as group 1). Due to clearly lower ap values, the results for Ti, $\mathrm{Ni}, \mathrm{W}$ and $\mathrm{Fe}$ (group 2) are shown with a changed scale.

The diagrams in Figure 4 show, that even for same process parameters and machining conditions the resulting ablation characteristics clearly differ for the investigated metals. For metals like lead or magnesium a values of about $600 \mathrm{~nm} /$ pulse and above can be realized, while for tungsten or iron $100 \mathrm{~nm} /$ pulse could not be achieved.

To get a more detailed overview about these differences, Table 2 summarizes the characteristic values for the ablation threshold $\mathrm{H}_{\text {th }}$, the values of $\mathrm{H}_{\text {therm }}$, the transition fluence $\mathrm{H}_{\text {trans }}$ and the achieved ablation rate per pulse $\mathrm{a}_{\mathrm{p}}$ at the transition fluence. Additionally, important optical and thermo physical properties (absorption coefficient $\alpha$ and calculated optical penetration depth $\delta_{\text {opt }}$, thermal diffusivity $\mathrm{D}$ and calculated thermal penetration depth $\delta_{\text {therm }}$, reflection coefficient $R$, melting temperature $T_{m}$, boiling temperature $T_{b}$, thermal conductivity $\kappa$ and specific heat capacity $c_{P}$ ) regarding the ablation behavior are shown. The metals in Table 2 are sorted by the values of $\mathrm{a}_{\mathrm{P}}$ from the highest $(\mathrm{Pb})$ to the lowest $(\mathrm{Fe}) . \mathrm{X} 20 \mathrm{Cr} 13$ is presented to complete the results for all investigated materials.

The optical penetration depth $\delta_{\text {opt }}$ has been calculated using the absorption coefficient $\alpha$ and equation 6 :

$$
\delta_{\text {opt }}=\frac{1}{\alpha}
$$

The thermal penetration depth $\delta_{\text {therm }}$ has been calculated using equation 7 with the thermal diffusivity $\mathrm{D}$ and the laser pulse duration $\tau_{\mathrm{P}}=12 \mathrm{ps}$.

$$
\delta_{\text {therm }}=\sqrt{D \cdot \tau_{P}}
$$

The optical penetration depth for the investigated metals shows values between $10 \mathrm{~nm}$ for $\mathrm{Al}$ and $26 \mathrm{~nm}$ for Ti. Group 2 shows higher values compared to group 1. Contrary, the calculated thermal penetration depth is in group 1 higher than in group 2, by trend, between $11 \mathrm{~nm}$ for Ti and $37 \mathrm{~nm}$ for $\mathrm{Cu}$.

For all metals in both groups the ablation rate $\mathrm{a}_{\mathrm{p}}$ correlates with the melting temperature $T_{m}$. This fact is obvious for group 1 , where $T_{m}$ increases continuously from $601 \mathrm{~K}$ $(\mathrm{Pb})$ up to $1360 \mathrm{~K}(\mathrm{Cu})$ and $\mathrm{a}_{\mathrm{P}}$ decreases (see Figure 4). Below the transition fluence $\mathrm{H}_{\text {trans }}, \mathrm{Mg}, \mathrm{Al}$ and $\mathrm{Cu}$ show related $a_{p}$ values. For higher fluencies the direct dependency to $T_{m}$ can be seen.

Beside the melting temperature $T_{m}$, the thermal conductivity $\kappa_{\text {th }}$ and specific heat capacity $c_{P}$ can also be used to explain the ablation behavior of $\mathrm{Pb}$. $\mathrm{Pb}$ shows, compared to the other metals in group 1 , low values for $\kappa_{\mathrm{th}}$ and $\mathrm{c}_{\mathrm{p}}$. In this case, the material heats up immediately and, simultaneously, the deposited energy will be conducted slowly into the surrounding material volume. The resulting heat buildup is indicated by the enormous $\mathrm{a}_{\mathrm{p}}$ values for $\mathrm{Pb}$.

The interdependency between $\kappa_{\text {th }}$ and $c_{P}$ can also explain the transition from non-thermal to thermal ablation.
$\mathrm{Mg}$ and $\mathrm{Al}$ show equal melting temperatures but have clearly different transition fluencies $\mathrm{H}_{\text {trans }}$. Both metals have nearly the same specific heat capacity in the range of $1 \mathrm{~J} / \mathrm{g} \cdot \mathrm{K}$ leading to comparable heating at the irradiated spot. The thermal conductivity is different for these two metals and therefore, for Al the deposited (thermal) energy is conducted faster into the surrounding material, due to the higher $\kappa_{\text {th }}$ value. Thus, the heat build-up and transition to thermal ablation were observed for $\mathrm{Al}$ at clearly higher fluence compared to $\mathrm{Mg}$.

Group 2 shows an equal ablation behavior regarding their thermo physical properties and the mentioned correlations but with lower differences between the resulting values of ap (see Figure 4).

There is one characteristic of group 2: The melting temperature of $\mathrm{W}$, which is twice as high as for the other metals in group 2 , should normally lead to the lowest $a_{\mathrm{p}}$ values. For fluencies near the ablation threshold this is the case. For higher fluencies the very low $c_{P}$ value of $0.13 \mathrm{~J} / \mathrm{gK}$ results in $\mathrm{a}_{\mathrm{p}}$ values which are comparable to $\mathrm{Ni}$ or $\mathrm{Fe}$, despite of the enormous melting temperature.

To sum up, the ablation rate per pulse $\mathrm{a}_{\mathrm{P}}$ is inverse proportional to the melting temperature $\mathrm{T}_{\mathrm{M}}$ and also depends on the thermal conductivity $\kappa_{\text {th }}$ and specific heat capacity $c_{\mathrm{P}}$. For higher values of these thermo physical properties the resulting values for $\mathrm{a}_{\mathrm{p}}$ decreases. Contrary to $\mathrm{a}_{\mathrm{p}}$, the transition fluence from non-thermal to thermal ablation $\mathrm{H}_{\text {trans }}$ shows a direct proportionality to the mentioned thermo physical properties. By these direct and inverse proportionalities it is obvious that higher ablation rates per pulse, by means of process efficiency, always attended by lower transition fluencies.

Beside the achieved values of $\mathrm{a}_{\mathrm{p}}$ and $\mathrm{H}_{\text {trans }}$, the ablation geometries also varied in terms of crater shape and burr formation. This fact is obviously demonstrated in Figure 5, for example for $\mathrm{Ti}$, representing group 2 , and $\mathrm{Cu}$, representing group 1. For Ti the ablation rate at $306 \mathrm{~mJ} / \mathrm{cm}^{2}$ is about $6 \mathrm{~nm} /$ pulse and at $7650 \mathrm{~mJ} / \mathrm{cm}^{2}$ about $55 \mathrm{~nm} /$ pulse. For $\mathrm{Cu}$ ablation rates of about $15 \mathrm{~nm} /$ pulse and $150 \mathrm{~nm} /$ pulse for the given fluencies are achievable. We observed an increased rate by a factor of 9 for $\mathrm{Ti}$ and 10 for $\mathrm{Cu}$.

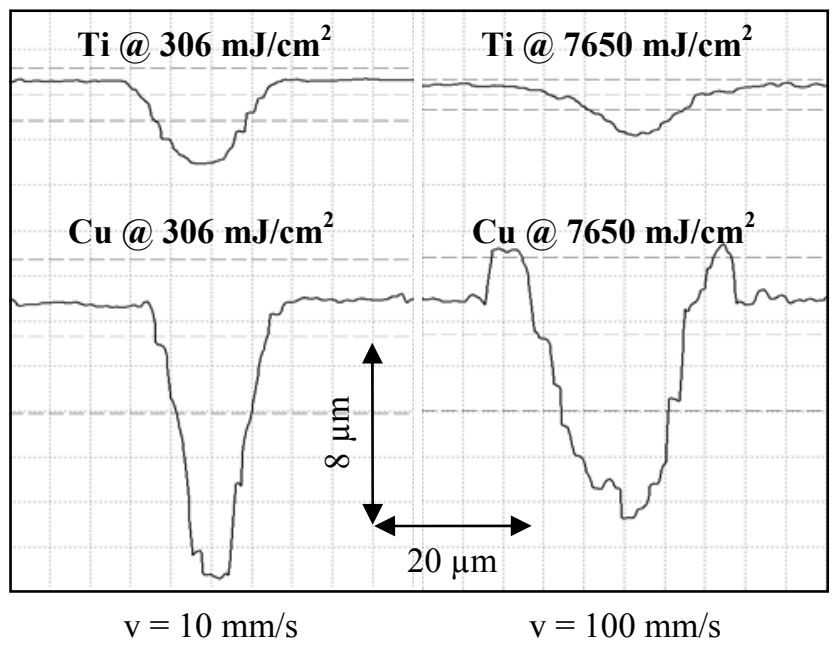

Figure 5: Cross section of line-shaped ablations for $\mathrm{Ti}$ and $\mathrm{Cu}$ using different fluencies 
Therefore, the feed rate has increased tenfold for the images shown on the right hand side to achieve comparable ablation depths for the two different fluencies. Given scales ( $8 \mu \mathrm{m}$ height and $20 \mu \mathrm{m}$ width) are valid for all shown profiles in Figure 5.

The two profiles on the left hand side of Figure 5 show the achieved cross sections of $\mathrm{Ti}$ and $\mathrm{Cu}$, when using a fluence of $\mathrm{H}_{\mathrm{P}}=306 \mathrm{~mJ} / \mathrm{cm}^{2}$ which is clearly below the transition fluence of both metals. The ablation depth for $\mathrm{Cu}$ $(\sim 12 \mu \mathrm{m})$ is about threefold higher than for $\mathrm{Ti}(\sim 4 \mu \mathrm{m})$ corresponding to the diagrams in Figure 4. In spite of the different ablation depth, a similar ablation width of about $20 \mu \mathrm{m}$ is observed. Both cross sections show well defined edges between unexposed and exposed surface without formation of burr along the irradiated areas.

When increasing the fluence above the transition regime, a difference in ablation depth by factor of 3.5 can be seen on the right hand side of Figure 5, also corresponding with Figure 4. Here, the area between exposed and unexposed surface is a gradual transition for Ti. The transition fluence of $\mathrm{Ti}\left(6571 \mathrm{~mJ} / \mathrm{cm}^{2}\right)$ is lightly exceeded, resulting in negligible melting effects. Contrary to Ti, the cross section for $\mathrm{Cu}$ shows an enormous burr formation on both sides of the crater, based on the clearly exceeded transition fluence of $2981 \mathrm{~mJ} / \mathrm{cm}^{2}$.

\section{Industrial application and relevance}

The results of section 3 show that there are physical limits for micro structuring of metals using ps pulse duration. On one hand side, the achievable ablation rate per pulse, by means of efficiency, varies for the investigated metals based on their thermo physical properties. On the other hand side, the transition from non-thermal to thermal ablation is in clear dependency of the fluence. For industrial applications these facts lead to the necessity to find a compromise between processing speed, by means of throughput, and quality, by means of thermal impact and burr formation.
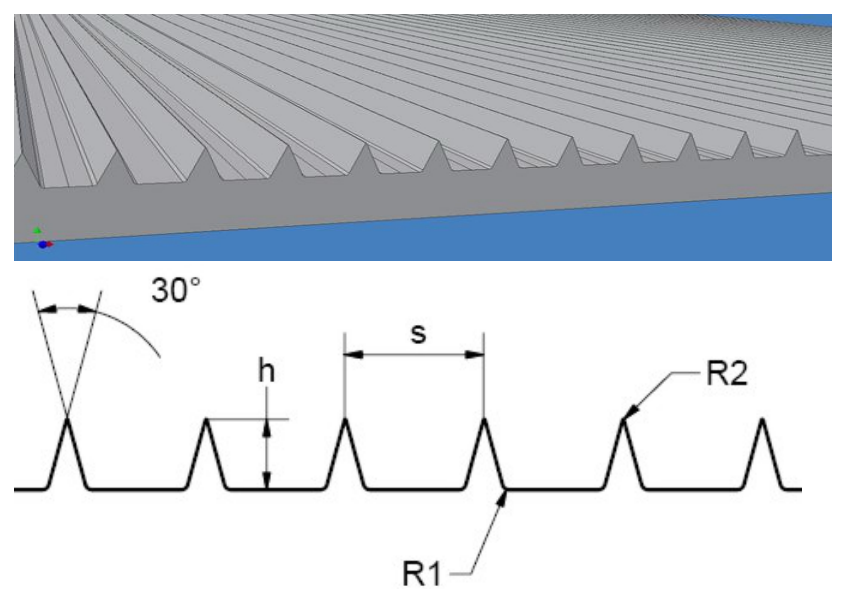

h riblet height $20 \mu \mathrm{m}$

s riblet width $40 \mu \mathrm{m}$

$\mathrm{R} 1$ bottom radius $1.5 \mu \mathrm{m}$

$\mathrm{R} 2$ tip radius $\quad 0.15 \mu \mathrm{m}$

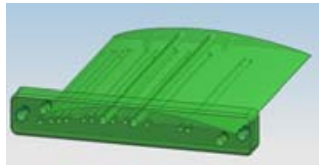

Figure 6: Ideal riblet geometry and NACA 6510
Within the following section we translate the presented results of basic considerations into the generation of extensive micro-structured surfaces for fluidic purposes.

\subsection{Generation of flow-optimized surfaces using exten- sive riblet structures}

Riblets are channel-structures aligned in stream wise direction on passed surfaces. Such structures have proven to reduce skin friction and wall shear stresses in turbulent flow up to $10 \%$ compared to smooth surfaces $[7,8]$.

The aimed geometry and dimensions, shown in Figure 6, were calculated by our project partners (Institute of Turbomachinery and Fluid Dynamics TFD Hannover, German Aerospace Center DLR Berlin). The flow conditions were simulated for the chosen profile, a NACA 6510 compressor profile made of $\mathrm{X} 20 \mathrm{Cr} 13$ with a chord length of $90 \mathrm{~mm}$ and $120 \mathrm{~mm}$ width. The ablation behavior of $\mathrm{X} 20 \mathrm{Cr} 13$ for the used pulse duration is presented in Figure 3 within section 3 .
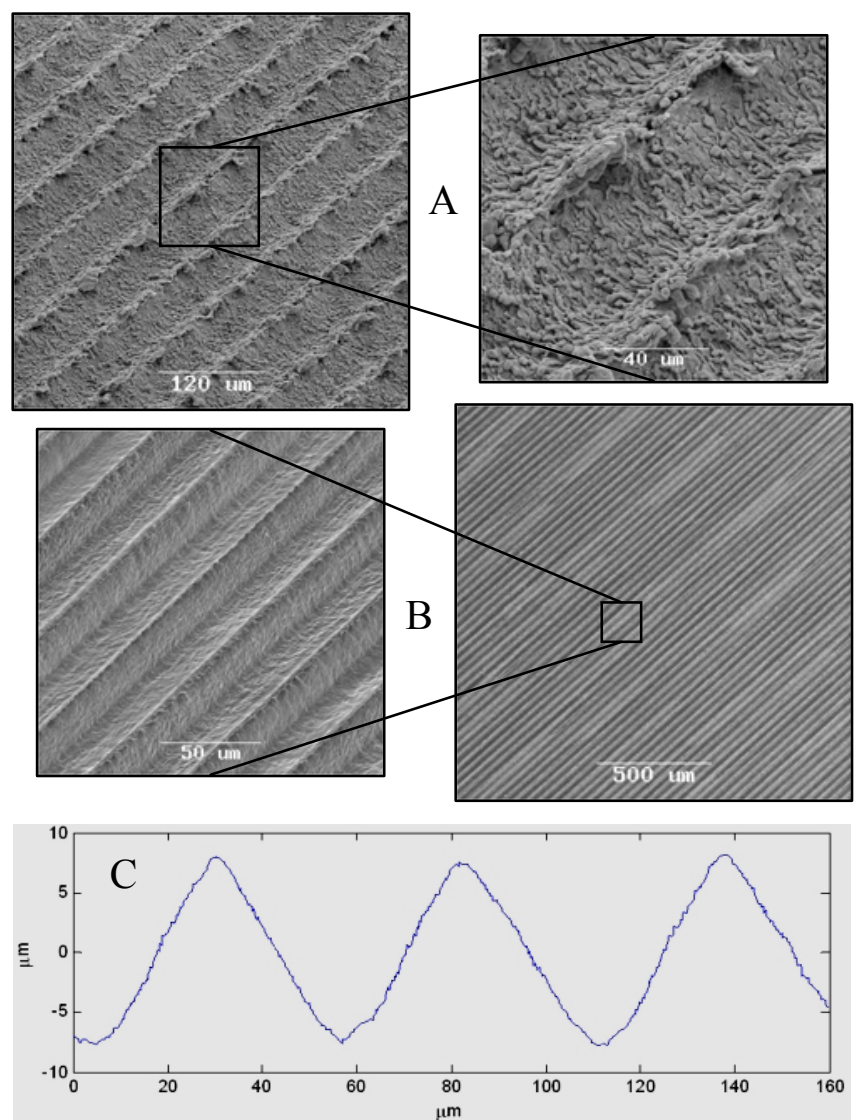

Figure 7: Extensive riblets for fluidic purposes

The riblet structures in Figure 7 are realized using a focused laser beam by scanning the surface line by line. The period of the riblet structures is simply defined by the distance between the lines, which is in the order of the spot diameter. Based on the presented ablation behavior and the found regimes (optical and thermal), different machining strategies and process parameters have been investigated. 
The SEM pictures in Figure 7A show results for a fluence $H_{P}=7650 \mathrm{~mJ} / \mathrm{cm}^{2}$, clearly above the transition fluence $\mathrm{H}_{\text {trans }}=3361 \mathrm{~mJ} / \mathrm{cm}^{2}$. These parameters lead to a throughput of about $5 \mathrm{~cm}^{2} / \mathrm{h}$. The influence of the high fluence is in particular observable by the completely molten material between the single lines. The riblets mainly consist of molten material. Such structures have very low stability and will be rapidly destroyed under high thermal or mechanical stress [9].

The riblets in Figure 7B are fabricated using a fluence of $\mathrm{H}_{\mathrm{P}}=3060 \mathrm{~mJ} / \mathrm{cm}^{2}$, which is in the range of transition fluence between the two regimes $\mathrm{H}_{\text {trans. }}$. Here the required ablation depth is $20 \mu \mathrm{m}$ resulting in $2.5 \mathrm{~cm}^{2} / \mathrm{h}$ throughput. Thermal damages like melting phases along the irradiated area, especially on the riblet tips, have been avoided.

The profile in Figure 7C, generated by a confocal microscope, gives a projection of the machined surface regarding periodicity as well as quality aspects in terms of burr height and surface roughness. These riblets have a height of about $15 \mu \mathrm{m}$ by $65 \mu \mathrm{m}$ width and were generated using quality-optimized process parameters.

\subsection{Results of linear cascade wind tunnel}

For the experimental investigations of the structured NACA profiles the test facility of our project partners from the Institute of Turbomachinery and Fluid Dynamics (TFD) in Hannover were used [7]. The test blade is divided into a test side carrying the riblet surface and a reference side which is smooth [7].

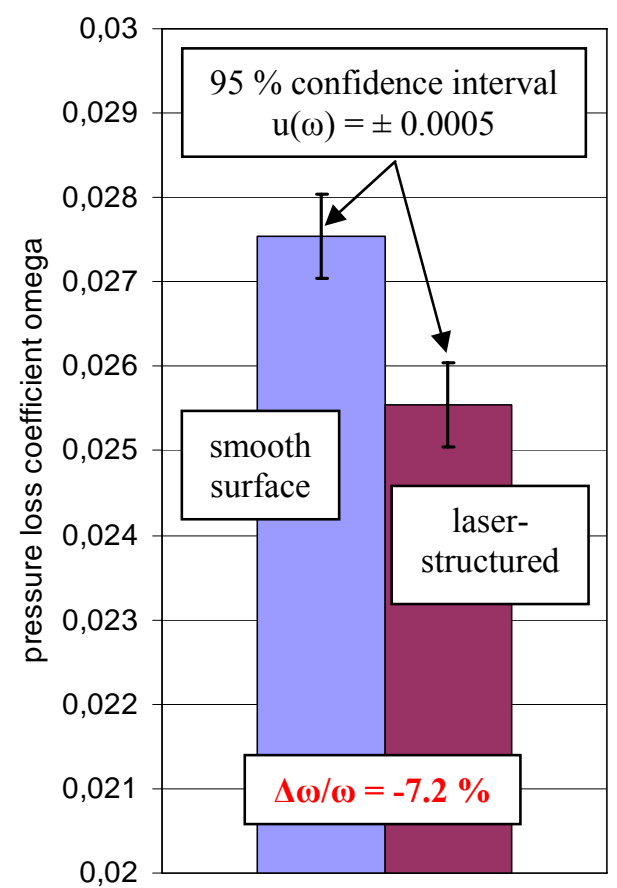

Figure 8: Effectivity gain [7]

It is obvious in Figure 8 that the structured surface reduces pressure loss, which is consistent with the results of the geometrical measurement done by the Institute for Measurement and Automatic Control Hannover (IMR). The geometry of the generated riblet surface is quite similar to the ideal one shown in Figure 6. A pressure loss reduction of $7.2 \%$, compared to the unmachined smooth reference surface, has been achieved.

\subsection{Industrial relevance}

It has been shown, that the use of ps pulse duration for extensive micromachining of metals is always a compromise between quality and efficiency. For the investigated pulse duration typical values for the ablation rate per pulse are in the range of several ten up to several hundred $\mathrm{nm} /$ pulse. The presented application, generation of extensive riblet-structured surfaces, shows the necessity of finding a compromise between quality and efficiency.

On one hand, a non-thermal ablation process with high reproducibility is required to fulfill the structure demands like small and sharp tip radius without any formation of burr. Therefore, low fluence values have to be used, leading to $a_{P} \leq 25 \mathrm{~nm} /$ pulse and consequently, throughput of about $2.5 \mathrm{~cm}^{2} / \mathrm{h}$. For the machined NACA 6510 with a machined area of $108 \mathrm{~cm}^{2}$ a processing time of about $40 \mathrm{~h}$ was necessary.

On the other hand, when accepting minor quality losses, the use of clearly higher fluencies above the materialspecific transition fluence leads to a throughput which can be doubled or tripled easily. In this case the processing time for NACA 6510 can be reduced to about $15 \mathrm{~h}$. To introduce further improvements in processing speed, the following approaches are possible.

The considerations and correlations presented in the paper always refer to single pulses by means of fluence per pulse as well as ablation rate per pulse. The fluence per pulse is limited regarding quality aspects, but the pulse repetition rate is a scalable parameter. Increasing this parameter and simultaneously, the feed rate should result in reduced processing time and increased throughput. Commercial ps laser sources allow repetition rates up to $1 \mathrm{MHz}$ at the required pulse energy, which is twentyfold higher than the used laser source. Such high repetition laser systems require adapted handling systems to ensure according dynamics and accuracy for the work piece handling.

Beside the system technology, the machining strategy is even more able to reduce the processing time. The presented machining strategy was a serial line-by-line machining. Here, the use of optical elements, such as multi spot (DOE), will allow parallelization of the limited highquality ablation rate. This will enable surface structuring with up to 50-times higher processing speed.

\section{Conclusions}

Micro-machining of nine different metals and a prospective application using picosecond pulses has been presented. Pulse duration in the range of $12 \mathrm{ps}$ is regarded as useful to minimize thermal damage and burr. Compared to nanosecond pulses, were ablation rates of about $10 \mu \mathrm{m}$ are common values [10], the achievable ablation rates for picosecond pulse duration are clearly lower, leading to increased processing time. On the other hand, the quality of ablated structures as well as the process resolution is close to femtosecond ablation when qualified process parameters 
are used. The given physical process limitations can not be avoided. However, adapted system technology, useful beam preparation as well as optimized machining strategies will be the key to bring picosecond laser micro-machining into real industrial applications.

\section{Acknowledgement}

We thank our project partners from the Institute of Turbomachinery and Fluid Dynamics (TFD) Hannover, the Institute for Measurement and Automatic Control (IMR) Hannover and the German Aerospace Center (DLR) Berlin.

This work is supported in part by the German Research Foundation (DFG) within the project 'Riblets on compressor blades' (OS 188/20-1).

\section{References}

[1] R. Kling et al: Picosecond Laser in Industrial Applications (Invited Paper), Proceedings of the $3^{\text {rd }}$ Pacific International Conference on Application of Lasers and Optics, Beijing, 2008

[2] U. Klug et al: Picosecond Laser Material Processing Prospects and Limitations, Proceedings of $25^{\text {th }}$ International Congress on Applications of Lasers \& ElectroOptics, Scottsdale, Ariz., 2006

[3] S. Sommer, M. Kraus, F. Dausinger: Surface structuring of technical metal surfaces with ultrashort laser pulses - enhancement of quality and efficiency, Proceedings of the $4^{\text {th }}$ International WLT-Conference on Lasers in Manufacturing, Munich, 2007

[4] H. K. Tönshoff et al: Micromachining of Metals Using Ultrashort Laser Pulses, International Journal of Electrical Machining, No. 4, 1999

[5] F. Dausinger, H. Hügel, V. Konov: Micro-machining with ultrashort laser pulses: From basic understanding to technical applications, Advanced Laser Technologies, Adelboden, $\mathrm{CH}, 2002$

[6] D. Bäuerle: Laser Processing and Chemistry. 3. Edition. Heidelberg: Springer Verlag, 2000. -ISBN 3-54066891-8

[7] K. Oehlert, J. R. Seume: Exploratory experiments of machined riblets on compressor blades. Proceedings of FEDSM2006 - 2006 ASME Joint U.S. - European Fluids Enigneering Summer Meeting, July 17-20, Miami, FL; FEDSM 2006 - 98093

[8] J. R. Seume et al: Exploratory Experiments on Machined Riblets for 2-D Compressor Blades, in Proceedings of ASME International Mechanical Engineering Congress and Exposition, DVD, Seattle, USA, 2007

[9] A. Ostendorf, F. Siegel, U. Stute: Laser-based Surface Modification - Micro Structures on Macro Areas, in Proceedings of the $2^{\text {nd }}$ Pacific International Conference on Applications on Lasers and Optics, DVD, Melbourne, Australia, 2006

[10]A. Schoonderbeek et al: The influence of the pulse length on the drilling of metals with an excimer-laser, in Journal of Laser Applications, Volume 16, Number 2, May 2004

[11]D. R. Lide: CRC Handbook of Chemistry and Physics, $82^{\text {nd }}$ Edition, 2001-2002, CRC Press

[12] M. A. Ordal et al: Optical Properties of the Metals Al, $\mathrm{Co}, \mathrm{Cu}, \mathrm{Au}, \mathrm{Fe}, \mathrm{Pb}, \mathrm{Ni}, \mathrm{Pd}, \mathrm{Pt}, \mathrm{Ag}$, Ti and $\mathrm{W}$ in the Infrared and far Infrared; In Applied Optics, Vol. 22, No. 7, April 1983

(Received: June 16, 2008, Accepted: May 28, 2009) 